\title{
Virtual Simulation Learning from Indonesian Nursing Students' Perspectives
}

\author{
Marisa Manik*(D), Eva Gultom (D), Renova Sibuea (D), Heman Pailak (D) \\ Faculty of Nursing, University of Pelita Harapan, Tangerang, Indonesia
}

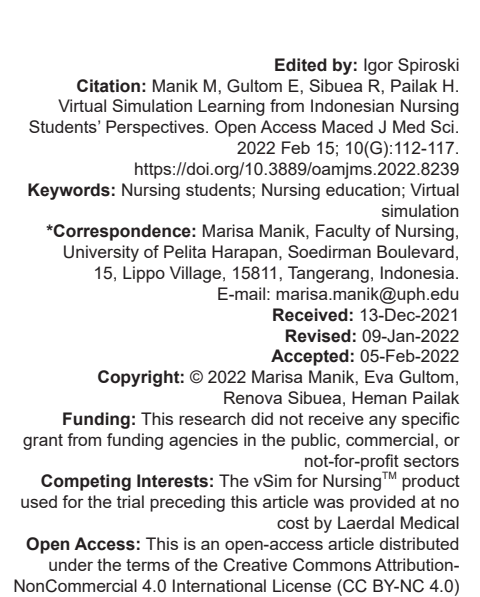

\begin{abstract}
BACKGROUND: Nursing education is shifting from face-to-face to online learning during the COVID-19 pandemic. Virtual simulation can be used to support online learning for nursing skills.

AIM: This study aimed to describe Indonesian nursing students' perspectives regarding the use of vSim for Nursing ${ }^{\mathrm{TM}}$ METHODS: This study used a mixed-methods approach by administering a set of electronic surveys to $503^{\text {rd }}$-year nursing students of the private institution in Tangerang, Indonesia, who participated in a vSim for Nursing ${ }^{\mathrm{TM}}$ trial program in October 2020. The quantitative data were analyzed using SPSS Statistics version 27 , and the qualitative data were analyzed using content analysis.

RESULTS: The results showed that $14 \%$ of respondents strongly agree, and $54 \%$ agree that virtual simulations are easy to use. As many as $54 \%$ of respondents agreed, and $32 \%$ strongly agreed that the virtual simulation content was relevant to a nurse's role, with most respondents (92\%) supporting future use. Four categories emerged from the qualitative data, including (1) Learning to think critically, (2) A realistic and safe learning environment, (3) Effectively improving learning, and (4) English language, internet networks, and unfamiliarity as barriers.
\end{abstract}

CONCLUSION: The findings support virtual simulation as a pedagogical approach, a clinical training method, and a learning supplement. This study is a starting point to develop a virtual simulation for nursing education in Indonesia.

\section{Introduction}

The COVID-19 pandemic significantly impacted the education sector. Nursing education has been especially affected due to substantial challenges in implementing the clinical practice component [1]. Nursing skills laboratory generally utilizes in-person simulations with mannequins and simulated patients. However, nursing education has had to be delivered online due to the pandemic. As an alternative, the virtual simulation was used to support online learning for nursing skills. The International Nursing Association of Clinical Simulation and Learning and the Society for Simulation in Healthcare support the use of virtual simulation to satisfy required clinical practice hours for health education students during the COVID-19 pandemic [2], as it is a technology effective for learning nursing skills [3].

Several virtual simulation products have been developed. One of which is the vSim product for Nursing $^{\mathrm{TM}}$, a collaboration between Wolters Kluwer Health (Lippincott), Laerdal Medical, and the National League for Nursing (NLN) in 2014 [3]. The vSim for Nursing $^{\text {TM }}$ uses a web-based platform containing several scenarios based on the nursing education curriculum, allowing students to interact with patients virtually, receive feedback on actions, and repeat the experience on-demand [4].

To date, there is no virtual simulation product utilized in Indonesia's nursing education, and it is still considered a novel approach. However, the pandemic in 2020 pushed nursing education in Indonesia to consider virtual learning modes. Over 1 month, an undergraduate nursing program in Indonesia trialed a virtual simulation product, vSim for NursingTM, to understand its feasibility. Subsequently, this paper aims to build on the trial by evaluating students' perspectives participating in the vSim for Nursing ${ }^{\mathrm{TM}}$ trial.

Simulation is a learning method used to replace or reinforce real experiences with guided experiences. It is not merely a technology, but an educational approach based on learning theories [5], which has historically been commonly used in nursing education to teach nursing skills. The first mannequin for training new nurses was created in 1911 [6]. Subsequently, in the 1990s, significant changes in educational simulations occurred with the emergence of health education technology companies that turned traditional laboratories into high-fidelity simulations [5]. 
Simulations are carried out with realistic clinical scenarios to help students develop non-technical skills, practice emergencies that rarely occur, and provide common patient care scenarios [7]. Nursing students who engage in simulated learning make fewer medical errors in the clinical setting, develop critical thinking skills, and make better clinical decisions [8].

Virtual simulation is a clinical simulation delivered through the computer, internet, or digital learning environment with a single user or multiuser platforms [9]. Virtual simulation using avatars through a virtual world is an exciting and meaningful way to teach high-level nursing skills [10]. It provides a realistic recreation depicted on a computer screen and involves real people in the simulation system's operation [11]. The NLN collaborated with Laerdal Medical and Wolters Kluwer Health to develop vSim for Nursing ${ }^{\mathrm{TM}}$ to help students build confidence and readiness for clinical practice [12]. Each product features ten virtual patient scenarios designed to simulate real nursing scenarios and develop clinical decision-making skills, competence, and confidence in nursing students. The vSim for Nursing ${ }^{\mathrm{TM}}$ includes online interactive virtual simulations with pre- and post-simulation tests integrated with curriculum resources, guided reflection questions, and interactive scenarios. It further provides personal feedback to the students, resulting in a meaningful simulation learning experience [13]. Due to its web-based nature and interactive features, students can interact with patients in a realistic and safe environment anytime and anywhere [12].

The use of vSim for Nursing ${ }^{\mathrm{TM}}$ as a laboratory activity provides a platform for practicing clinical decisionmaking skills, as it not only focuses on practical skills butalso encourages critical thinking regarding the implementation of psychomotor abilities [14]. Based on a systematic review and meta-analysis of 80 research studies from 1996 to 2018 , most studies ( $n=69,86 \%$ ) support virtual simulation as an effective pedagogical method to support learning outcomes [15]. Another systematic review on the effectiveness of virtual patient simulations from 1990 to 2018 found effective improvements in skills, including clinical reasoning, procedural skills, and a combination of procedural and teamwork skills [16]. The vSim for Nursing ${ }^{\mathrm{TM}}$ has never been used in Indonesia's nursing education. There are several considerations in using this product, such as the English language in this product, the content based on the United States nursing education curriculum, and the cost of the product. approaches. The questionnaire used in this study was developed by Foronda et al. [9], and permission for use was obtained from the author. The questionnaire was translated to Indonesian by a sworn translator. The questionnaire consisted of nine items, including two questions involving rating on a Likert scale (1 representing strongly disagree and 5 representing strongly agree) regarding the easiness of navigation content and relevance to a nurse's role, two yes/ no questions, five open-ended questions about the learning key points and students' experiences using the vSim for Nursing ${ }^{\mathrm{TM}}$, and one ranking question to rank the usefulness of vSim for Nursing ${ }^{\mathrm{TM}}$ components. This study was conducted at a private undergraduate nursing institution in Tangerang, Indonesia. Fifty $3^{\text {rd }}$-year undergraduate nursing students who participated in the vSim for NursingTM trial program in October 2020 were recruited using a total sample technique. Ethics approval was granted by the Ethics Committee of the Mochtar Riady Institute for Nanotechnology (MRIN) under permit number 025/MRIN-EC/ECL/X/2020.

\section{Data collection}

The vSim for Nursing ${ }^{\mathrm{TM}}$ trial that preceded this study took approximately $160 \mathrm{~h}$ over 3 weeks. The simulations in this trial consisted of medical surgical nursing scenarios. Each student was given two virtual simulation trials and a debriefing session with trained virtual simulation facilitators at the end. Data collection for the survey began within $24 \mathrm{~h}$ after each student finished the virtual simulation. Researchers administered the questionnaire electronically using Microsoft Office Form and distributed the link to participants through the WhatsApp Messenger application.

\section{Data analysis}

Quantitative data were processed and analyzed using SPSS Statistics version 27 to generate descriptive statistics. For questions with yes/no answers, the data are presented as a percentage with a total of $100 \%$. The qualitative data were obtained through open-ended questions in the same questionnaire and were analyzed using the content analysis method by the research team independently.

\section{Results}

\section{Descriptive quantitative}

The majority of respondents were women (84\%) aged 20 years (66\%), 46\% of whom had English proficiency in the "sufficient" category, and $30 \%$ in the "good" category (Table 1). quantitative descriptive and qualitative descriptive 
Table 1: Distribution of Respondent Characteristics Based on Gender, Age, and English Language Ability $(n=50)$

\begin{tabular}{lll}
\hline Category & Frequency $(\mathrm{n})$ & Percentage $(\%)$ \\
\hline Sex & 8 & \\
$\quad$ Male & 42 & 16 \\
$\quad$ Female & & 84 \\
Age & 2 & \\
18 years & 10 & 4 \\
19 years & 33 & 20 \\
20 years & 4 & 66 \\
21 years & 1 & 8 \\
22 years & 1 & 2 \\
English language ability & 15 & 2 \\
Very good & 23 & 30 \\
Good & 11 & 46 \\
Sufficient & & 22 \\
Low & & \\
\hline
\end{tabular}

Regarding the easiness of navigating the virtual simulation program, $14 \%$ of respondents strongly agreed to the statement, and $54 \%$ agreed, and only $2 \%$ strongly disagreed. The data also show that $54 \%$ of respondents agreed and $32 \%$ strongly agreed that this virtual simulation content is relevant to a nurse's role (Table 2).

Table 2: Distribution of respondents based on evaluation questions using vSim for nursingTM from the perspective of nursing students $(n=50)$

\begin{tabular}{llllll}
\hline Questions & $\begin{array}{l}\text { Strongly } \\
\text { disagree } \\
\mathrm{n}(\%)\end{array}$ & $\begin{array}{l}\text { Disagree } \\
\mathrm{n}(\%)\end{array}$ & $\begin{array}{l}\text { Neutral } \\
\mathrm{n}(\%)\end{array}$ & $\begin{array}{l}\text { Agree } \\
\mathrm{n}(\%)\end{array}$ & $\begin{array}{l}\text { Strongly } \\
\text { agree } \\
\mathrm{n}(\%)\end{array}$ \\
\hline $\begin{array}{l}\text { Was the simulation easy to } \\
\text { navigate? }\end{array}$ & $1(2)$ & $5(10)$ & $10(20)$ & $27(54)$ & $7(14)$ \\
$\begin{array}{l}\text { The content of this virtual } \\
\text { simulation was directly } \\
\text { relevant to my role as a nurse }\end{array}$ & $1(2)$ & $0(0)$ & $6(12)$ & $27(54)$ & $16(32)$ \\
\hline
\end{tabular}

Furthermore, 46 respondents (92\%) recommended this virtual simulation for future use. The last question asked the respondents to rank the usefulness of $\mathrm{vSim}$ for Nursing ${ }^{\mathrm{TM}}$ components. It was found that the component that had the highest percentage of importance ranking was the simulation program being a substitute for the case study in lectures (improving lectures) at 38\%, followed by being a make-up for insufficient clinical practice hours at $36 \%$ (Figure 1)

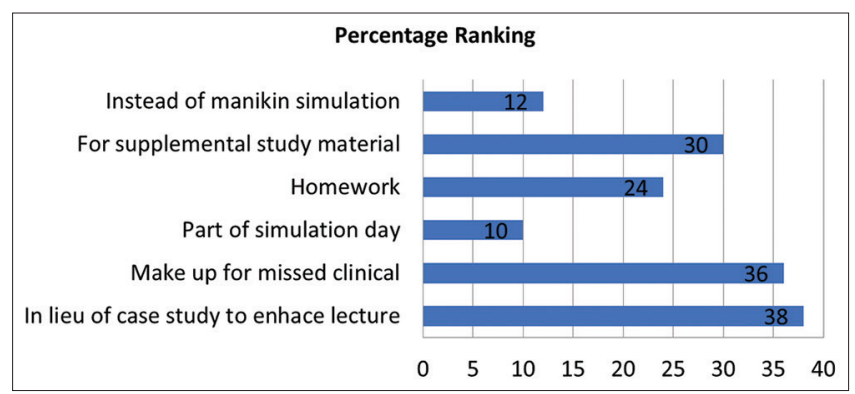

Figure 1: Student responses about where the simulation fits within the curriculum

\section{Descriptive qualitative}

This study had five open-ended questions about the learning key points and students' experiences using the vSim for Nursing ${ }^{\mathrm{TM}}$. Four categories emerged from the qualitative data regarding the evaluation of
vSim for nursing ${ }^{\mathrm{TM}}$ from nursing students' perspective: (1) Learning to think critically, (2) A realistic and safe learning environment, (3) Effectively improving learning, and (4) English language, internet networks, and unfamiliarity as barriers.

The category of learning to think critically was expressed repeatedly in the qualitative data. Some of the examples of student responses are listed below:

- "I learned to think critically to decide what action I should take next."

- $\quad$ "From this simulation, I learned that we must be careful, precise, and fast in providing care interventions for the patient. The wrong intervention can endanger the patient, and if you take care of the patient, do not panic, especially in an emergency, so there will be no error, and you have to think critically."

- $\quad$ "I learned to be more critical, knowledgeable, and skillful in dealing with patients."

- "I learned to think critically and systematically, even virtually."

- $\quad$ "I learned to think critically like a nurse and take the right action without risking the patient's life."

A second category that emerged was that virtual simulation provided a realistic and safe learning environment, as demonstrated in students' remarks:

- "I can learn to handle patients independently and be more courageous about taking action."

"I can study freely without fear.

- $\quad$ "I can train my ability to provide care to patients because it is more stressful in the clinic, and sometimes I can't take targeted actions directly."

- $\quad$ "At least in this simulation, I can still be wrong, and I use that error as an evaluation so that when I meet a real patient with this condition, I will not repeat the mistakes I made."

"Virtual patients look real in that they respond." "It helps in improving my skills. When I practice in the hospital, I'm afraid to take action because I'm not ready for the patient. However, this simulation makes me more confident in the future when dealing with patients directly."

The students also described virtual simulations were effective in improving their learning. This description was the third category. The students described:

- $\quad$ "Effective because we can get direct experience in providing nursing care. Patients also have various responses, so I am trained to pay close attention to the patient's situation/ case in the simulation. There are also pretest and post-test."

- $\quad$ "Very effective. This virtual simulation is like going directly to the patient. In this simulation, the patient also responds so that we know 
when we do something to the patient, we can find out how the patient responds to our intervention."

"I feel like I'm really in front of the patient in person, and it is perfect to be used as a lesson when dealing with real patients 1 day."

"Useful because in this vSim, there are also many evidence-based practices and the rationale for taking specific intervention actions on patients."

The fourth category was English language, internet networks, and unfamiliarity as barriers. Many students also reported a number of obstacles during the virtual simulation trial.

"The language barrier, because I am not fluent in English, is my $1^{\text {st }}$ time using this, so I'm still confused about using it."

- "When I was doing the simulation, my internet network was down, so I had to restart from the beginning, and my English is not good."

- "We need to improve our English skills because this vSim is entirely in English.

- When doing this simulation, there are some English words, and many features are not understood."

"Network problems and unfamiliar with the virtual simulation menu."

\section{Discussion}

\section{Quantitative}

Findings indicate that most respondents agree that virtual simulation was easy to navigate, and that virtual simulation content is directly relevant to a nurse's role. Almost all respondents recommended this virtual simulation for future use. These results align with other virtual simulation studies carried out in nursing education [3], [4], [9]. The ease of using virtual navigation may also be related to the characteristics of respondents who are in the age range of 18-22 years, known as Generation Z, characterized as consumers who are appealed by technology and the digital world, or also known as "true digital natives" [17]. At present, students who are undertaking nursing education use social media and play video games daily, reflecting their level of comfort and familiarity with technology [18]. A systematic review finds that $51 \%$ of studies conducted between 1996 to 2018 show high learner satisfaction after using virtual simulations [15]. Students described the virtual simulation experience as enjoyable, fun, and easy-to-use [15], making it incredibly useful to support learning.

Technology in nursing education has undergone rapid development, as studies show various virtual simulation products are produced by nursing lecturers and researchers [15]. One of the products tested on students in this study was developed by Wolters Kluwer Health (Lippincott), Laerdal Medical, and the NLN in 2014 [3]. This collaboration resulted in a virtual simulation that contains relevant learning content to prepare students for the nurse's roles. The ease of use and convenience in this technology also encourage students to use this virtual simulation in future learning as was observed through responses of students participating in vSim for Nursing ${ }^{\mathrm{TM}}$ trial who see it useful to enhance lectures or as to make-up for lack of clinical practice hours. Given the current circumstances of the COVID-19 pandemic, face-to-face learning has shifted to virtual learning, and clinical practice has been deferred to protect students from infection exposure. While classroom learning can be converted quickly to virtual class meetings using platforms such as Moodle, Zoom, Microsoft Teams, and Google Classroom, among others, the same does not apply to laboratory and clinical learning [19].

Virtual simulation is an effective solution to concerns in the nursing training process, especially when students cannot be physically present. Clinical virtual simulation proves to be an innovative technology that is effective because students can interact with virtual patients in a realistically simulated environment [20], serving as a promising method for virtual nursing training in Indonesia.

\section{Qualitative}

In the qualitative portion of the study, most respondents stated that they learned to think critically through the use of virtual simulations. This is consistent with the findings from the study by [8], where nursing students involved in simulation learning were able to develop their critical thinking skills and significantly improve their clinical decision-making. A recent study also showed that vSim for Nursing ${ }^{\mathrm{TM}}$ improved students' critical thinking skills [21]. Our study results are also in line with a review, which demonstrated that virtual simulations had been used effectively to increase knowledge, skills, critical thinking, and provide self-confidence [15]

Students stated that they can learn freely without fear in virtual simulation as this learning method allows them to make mistakes. They can use these mistakes as feedback to prevent similar mistakes with real patients, as indicated by virtual simulation evaluation studies in Norway [4]. Our findings also suggest that the simulation method further allows students to practice their clinical skills repeatedly, to learn at their desired pace, to make mistakes within a safe environment [8]. It provides opportunities for students to interact with virtual patients in a real, created environment and a constructive learning environment [20].

The majority of students stated that virtual simulation learning effectively improved their learning, 
especially during the COVID-19 pandemic, which required them to take online learning. Virtual simulation through vSim for Nursing ${ }^{\mathrm{TM}}$ provides an opportunity for students to be actively involved in virtual clinical scenarios, providing a powerful impact on the psychomotor domain [7], positively impacting learning outcomes [15].

Although the virtual simulation was easy to navigate, students also reported challenges in using vSim for Nursing ${ }^{\mathrm{TM}}$ as the product is entirely in English. Despite some students (30\%) reporting their English skills as good and sufficient, they still experience a language barrier to an extent. Similar constraints were reported in an evaluation study of vSim for Nursing ${ }^{\mathrm{TM}}$ in Norway [4]. In addition, students conveyed difficulties in using the tools available in the vSim for Nursing ${ }^{\mathrm{TM}}$ which could be attributed to this experience being their first virtual simulation, therefore less familiar with the various menu options.

Students who participated in the vSim for Nursing $^{\mathrm{TM}}$ trial were spread across multiple cities and villages in Indonesia. Some participants who reside in geographically remote areas experienced constraints with an internet connection required to access the simulation program. This promising learning solution through online platforms also presents a new problem, such as limited internet access [19]. As the COVID-19 pandemic has significantly disrupted nursing education, there is an urgent need to provide clinical education to students under these uncertain conditions [1]. As such, the vSim for Nursing ${ }^{\mathrm{TM}}$ can be incorporated as an addition to existing curricular activities to improve courses' learning outcomes [14].

\section{Limitations}

This study's limitations are the small sample size and only involve one nursing education institution in Indonesia. These factors limit the generalizability of the study findings but provide valuable perspectives regarding the acceptability and feasibility of using virtual simulations in nursing education, especially in Indonesia. Another limitation is that the questionnaire's reliability and validity test was not repeated prior to this trial but only used the questionnaire from previous research [9].

\section{Conclusion}

Evaluation of the use of vSim for Nursing ${ }^{\mathrm{TM}}$ from the perspective of nursing students in Indonesia showed that virtual simulation is useful, well-accepted, perceived to improve critical thinking skills, as well as enhanced learning through a realistic and safe environment. This virtual simulation product provided a new learning experience for students, can be used as an innovative pedagogical approach, clinical training method, part of a lab simulation activity, or as a supplement to increase knowledge and learning. Considerations in utilizing virtual simulations such as vSim for Nursing ${ }^{\mathrm{TM}}$ should include language barriers, the internet network's stability, and familiarization with the product. The findings from this study point to a need for nursing education in Indonesia to develop a virtual simulation product that is contextualized to the Indonesian nursing curriculum and considering the language of delivery.

\section{References}

1. Lazenby M, Chambers S, Chyun D, Davidson P, Phil K, Norman I, Tlou S. Clinical nursing and midwifery education in the pandemic age. Int Nurs Rev. 2020;67(3):323-5. https://doi. org/10.1111/inr.12601

PMid:32578218

2. INACSL and SSH. COVID-19: SSH/INACSL Position Statement on Use of Virtual Simulation during the Pandemic; 2020. Available from: https://www.ssih.org/Home/ctl/ArticleView/ $\mathrm{mid} / 54750 /$ articleld/2238/COVID-19-SSHINACSL-positionstatement-on-use-of-virtual-simulation-during-the-pandemi [Last accessed on 2020 Nov 15].

3. Foronda CL, Swoboda SM, Hudson KW, Jones E, Sullivan N Ockimey $\mathrm{J}$, et al. Evaluation of vSIM for nursing ${ }^{\mathrm{TM}}$ : A trial of innovation. Clin Simul Nurs. 2016;12(4):128-31. http://dx.doi. org/10.1016/j.ecns.2015.12.006

4. Tjoflat I, Brandeggen TK, Strandberg ES, Dyrstad DN, Husebo SE. Norwegian nursing students' evaluation of vSim for nursing. Adv Simul. 2018;3:10. https://doi.org/10.1186/ s41077-018-0070-9

PMid:29946485

5. Aebersold M. Simulation-based learning: No longer a novelty in undergraduate education. OJIN. 2018;23(2):412-8. https://doi. org/10.3912/OJIN.Vol23No02PPT39

6. Weir W. At 101, 'Mrs. Chase is a Medical Marvel; 2012. Available from: https://www.courant.com/health/hc-xpm-2012-03-29-hcmrs-chase-hartford-hospital-0328-20120327-story.html [Last accessed on 2020 Nov 15].

7. Kim J, Park J, Shin S. Effectiveness of simulation-based nursing education depending on fidelity: A meta-analysis. BMC Med Educ. 2016;16:152. https://doi.org/10.1186/s12909-016-0672-7

8. Eyikara E, Baykara ZG. The importance of simulation in nursing education. World J Educ Technol. 2017;9(1):2-7.

9. Foronda CL, Swovoda SM, Henry MN, Kamau E, Sullivan N, Hudson KW. Student preferences and perceptions of learning from vSim for Nursing ${ }^{\mathrm{TM}}$. Nurse Educ Pract. 2018;33:27-32. https://doi.org/10.1016/j.nepr.2018.08.003 PMid:30223110

10. Foronda C, Bauman EB. Strategies to incorporate virtual simulation in nurse education. Clin Simul Nurs. 2014;10(8):412-8. https://doi.org/10.1016/j.ecns.2014.03.005

11. Padilha JM, Machado PP, Ribeiro A, Ramos J, Costa P. Clinical virtual simulation in nursing education: Randomized controlled trial. J Med Internet Res. 2019;21(3):e11529. https://doi. org/10.2196/11529

PMid:30882355 
12. National League for Nursing. (n.d.). Centers for Nursing Education: vSim for Nursing. Available from: http://www.nln. org/centers-for-nursing-education/nln-center-for-innovationin-education-excellence/institute-for-simulation-andtechnology/vsim-for-nursing-medical-surgical [Last accessed on 2020 Nov 15].

13. Laerdal Medical. Virtual Simulation. vSim- for Nursing; 2020. Available from: https://www.laerdal.com/products/courseslearning/virtual-simulation/vsim-for-nursing [Last accessed on 2020 Nov 15].

14. National League for Nursing. 2015. vSim for Nursing: Implementation Guide for Faculty. Available from: http://www.nln. org/centers-for-nursing-education/nln-center-for-innovation-ineducation-excellence/institute-for-simulation-and-technology/ vsim-for-nursing-medical-surgical/vsim-implementationguides2 [Last accessed on 2020 Nov 15]

15. Foronda C, Fernandez-Burgos M, Nadeau C, Kelley C, Henry MN. Virtual simulation in nursing education: A systematic review spanning 1996 to 2018. Simul Healthc. 2020;15(1):4654. https://doi.org/10.1097/SIH.000000000000041 PMid:32028447

16. Kononowicz AA, Woodham LA, Edelbring S, Stathakarou N, Davies D, Saxena N, et al. Virtual patient simulations in health professions education: Systematic review and meta-analysis by the digital health education collaboration. J Med Internet Res. 2019;21(7):e14676. https://doi.org/10.2196/14676

PMid:31267981

17. Chicca J, Shellenbarger T. Connecting with generation Z: Approaches in nursing education. Teach Learn Nurs. 2018;13:180-4. https://doi.org/10.1016/j.teln.2018.03.008

18. Kinder FA, Kurz JM. Gaming strategies in nursing education. Teach Learn Nurs. 2018;13:212-4. https://doi.org/10.1016/j. teln.2018.05.001

19. Agu CF, Stewart J, McFarlane-Stewart N, Rae T. COVID-19 pandemic effects on nursing education: Looking through the lens of a developing country. Int Nurs Rev. 2021;68(2):153-8. https://doi.org/10.1111/inr.12663

PMid:33513283

20. Chan MM, Yu DS, Lam VS, Wong JY. Online clinical training in the COVID-19 pandemic. Clin Teach. 2020;17:445-6. https://doi. org/10.1111/tct.13218

PMid:32643184

21. Everett-Thomas R, Joseph L, Trujillo G. Using virtual simulation and electronic health records to assess student nurses' documentation and critical thinking skills. Nurs Educ Today. 2021;99:104770. https://doi.org/10.1016/j.nedt.2021.104770 PMid:33516978 